\title{
Anatomia do Caule de Lycopersicon esculentum Mill., Submetido A Diferentes Tratamentos Com Reguladores Vegetais
}

\author{
Maria Bernadete Gonçalves Martins ${ }^{* 1}$ and Paulo Roberto de Camargo e Castro ${ }^{2}$ \\ ${ }^{1}$ Departamento de Botânica, Instituto de Biociências, Letras e Ciências Exatas (IBILCE), Universidade Estadual \\ Paulista -UNESP, C.P. 136, CEP 15.054.000, São José do Rio Preto, SP; ${ }^{2}$ Departamento de Botânica, Escola \\ Superior de Agricultura "Luiz de Queiroz", ESALQ-USP, C.P.9, CEP 13.418.900, Piracicaba, SP.
}

\begin{abstract}
The effects of plant growth regulators $\mathrm{GA}_{3} 50 \mathrm{mg} . \mathrm{L}^{-1}$, NAA $100 \mathrm{mg} . \mathrm{L}^{-1}$, CCC $1500 \mathrm{mg} . \mathrm{L}^{-1}$ and SADH $3000 \mathrm{mg} . \mathrm{L}^{-}$ ${ }^{1}$ on stem anatomy of Lycopersicon esculentum Mill cv. Ângela Gigante were studied. Two sets of experiments were carried out in greenhouse during two separte periods. Anatomical studies, revealed that growth promotors induced increased xylem thickness and increased the number of tracheary elements while the growth retardants decreased xylem thickness and induced fiber formation.
\end{abstract}

Key words- plant growth regulators, anatomy, stem, Lycopersicon esculentum.

\section{INTRODUÇÃO}

O estudo de reguladores vegetais em plantas tem crescido rapidamente e tem levado ao desenvolvimento de tecnologias necessárias para o controle do crescimento de culturas agrícolas. Essas substâncias podem alterar diferentemente os órgãos das plantas, influenciando na morfologia da mesma.

A reduzida quantidade de substâncias naturais de crescimento que se encontram nas plantas, controlam seu crescimento e desenvolvimento. Com freqüencia em muitas plantas agrícolas, pode-se modificar esses processos mediante a aplicação de reguladores vegetais.

Hathout et al.(1993a), estudaram o efeito do IAA na morfologia e no metabolismo de tomateiros, verificando que pulverização de partes vegetativas com IAA $80{\mathrm{mg} . \mathrm{L}^{-1}}^{-1}$ promoveram o máximo crescimento do caule principal, sendo que a atividade do IAA na absorção de elementos minerais foi aumentada com IAA $10 \mathrm{mg} . \mathrm{L}^{-1}$. Apesar de vários avanços tecnológicos empregados nesta cultura em nossas condições, são poucos os estudos sobre o comportamento do tomateiro mediante utilização de reguladores vegetais, sendo que as pesquisas efetuadas visam solucionar principalmente problemas culturais prioritários tais como: irrigação, adubação, uso de defensivos no controle de pragas e doenças, programas de melhoramento genético e outras práticas.

Hathout et al.(1993 b) estudaram o efeito do IAA no conteúdo de hormônios endógenos de tomateiros e observaram que a aplicação de IAA $10 \mathrm{mg} . \mathrm{L}^{-1}$ em pulverização foliar, causou efeitos estimulatórios no crescimento, na diferenciação e no desenvolvimento das plantas. Entretando, alta concentração de IAA( $80 \mathrm{mg} . \mathrm{L}^{-1}$ ) induziu efeito inibitório, aumentando o nível e a atividade de inibidores endógenos e redução do nível de auxinas, giberelinas e citocininas, induzindo um desequilíbrio hormonal.

Estudos dos efeitos fisiológicos de reguladores vegetais, são efetuados visando o conhecimento da ação estimulatória ou inibitória no crescimento e desenvolvimento das plantas. Porém, essa idéia está sendo alterada com o desevolvimento de novas pesquisas que têm demonstrado que as mudanças morfológicas da

\footnotetext{
* Autor para correspondência
} 
planta estão associadas a alterações metabólicas, ou então, que o estado nutricional da planta, tem um importante efeito nas modificações morfológicas induzidas por reguladores vegetais.

Stand (1961), verificou um aumento significativo no comprimento de fibras em Corchorus olitorius L., Hibiscus cannabinus L. $e$ Cannabis sativa $L$., pulverizadas com giberelina. Gonçalves (1984) verificou que a giberelina diminuiu a quantidade de fibras esclerenquimáticas ao redor dos feixes vasculares de cana-de-açúcar 'NA 56-79', sendo que Wareing (1958) verificou que aplicação exógena de auxina, resulta na divisão cambial associada com a formação de vaso e lignificação em caule de choupo, Populus nigra v. itálica e freixo, Fraxinus excelsior. Hejnowicz \& Tomaszewski (1969) sugeriram que deve haver certo balanço entre giberelina e auxina para se obter uma máxima diferenciação do xilema. OTA et al.(1964) estudando a aplicação de CCC em plantas de tabaco e batata, observaram redução no comprimento internodal, resultando em pequeno crescimento das plantas.

O objetivo deste trabalho, foi efetuar um estudo anatômico comparativo do caule de tomateiros submetidos a diferentes tratamentos com biorreguladores, através de secções transversais do caule na região mediana e a $5 \mathrm{~cm}$ do solo.

\section{MATERIAL E MÉTODOS}

Utilizaram-se no presente trabalho, tomateiros (Lycopersicon esculentum Mill. cv. Ângela Gigante), planta com hábito de crescimento indeterminado, excelente uniformidade e alta produtividade. Para se estudar a ação de reguladores vegetais na anatomia do caule, na região mediana e na região a $5 \mathrm{~cm}$ do solo, o experimento foi instalado e conduzido em casa de vegetação no Horto Experimental do Departamento de Botânica, da Escola Superior de Agricultura "Luiz de Queiroz", ESALQ-USP, Piracicaba (SP).

Inicialmente, efetuou-se a semeadura de tomateiros, em caixas de plástico, contendo terra esterilizada. Catorze dias após a semeadura, as mudas mais vigorosas foram selecionadas e transplantadas para vasos com capacidade de 12 L de terra, constituída de uma mistura de solo argiloso, areia e matéria orgânica (2:1:1), além da aplicação de uma adubação mineral complementar de N, P, K (12:14:8); 10 gramas por vaso. Foram aplicados semanalmente, o inseticida Folidol $1 \mathrm{ml} . \mathrm{L}^{-1}$ de água e o fungicida Cobre Sandoz $\quad 1,5 \mathrm{~g} . \mathrm{L}^{-1}$ de água.

Quando as plantas atingiram o estágio de quatro folhas definitivas, realizaram-se pulverizações com giberelina ( KGA 2\%, Gibrel), também denominada de $\mathrm{GA}_{3}$, na concentração de 50 mg. $\mathrm{L}^{-1}$; auxina (NAA 20\% Nafusaku, da Okochi), ácido naftalenacético, NAA 100 mg.L '; chlormequat (Cycocel 50\%, da Cyanamid), cloreto( 2-cloroetil) trimetilamônio, CCC 1500 mg. $\mathrm{L}^{-1}$ e daminozide (Alar, $85 \%$, da Uniroyal ), ácido succínico -2,2- dimetilhidrazida, SADH $3000 \mathrm{mg} . \mathrm{L}^{-1}$, além da testemunha. Foi utilizado o espalhante adesivo Novapal $0,1 \%$ em todas as soluções. O delineamento estatístico utilizado foi inteiramente casualizado, tendo-se cinco tratamentos com dez repetições.

O estudo anatômico do caule foi realizado na região de entrenó, a $5 \mathrm{~cm}$ do solo e na região mediana, aos 10 e 20 D.A.T. (dias após o tratamento). Inicialmente os caules foram coletados e fixados em F.A.A. Efetuaram-se secções transversais feitas à mão livre com gilete, seguidas da descoloração do material em hipoclorito de sódio 20\%. Os cortes foram montados em lâminas semipermanentes, com gelatina glicerinada, corado com verde-iodoacético e vermelho Congo ( Dop \& Gautié, 1909). Nessas lâminas, foram efetuadas medições em $\mu \mathrm{m}$, através de ocular micrométrica da : altura das células epidérmicas, espessura do córtex, espessura do colênquima e espessura do xilema e do floema na região interfascicular. As áreas foram determinadas através da utilização da ocular em quadrante, expressa em $\mathrm{mm}^{2}$ (área de xilema e de floema na região fascicular ).

As fotomicrografias referentes aos aspectos anatômicos dos caules de tomateiros foram obtidas, através de fotomicroscópio axioplan 
(Zeiss), utilizando-se filme T Max, Kodak, asa $100,135 \mathrm{~mm}$.

\section{RESULTADOS E DISCUSSÃO}

Os efeitos dos biorreguladores vegetais sobre a anatomia do caule, aos 10 e 20 D.A.T., em seções de entrenó a $5 \mathrm{~cm}$ do solo e na região mediana, podem ser observados nas Figuras 1 a 7. As variáveis quantitativas referentes ao caule de tomateiros submetidos aos efeitos de reguladores vegetais como, altura de células epidérmicas, espessura do córtex, espessura do colênquima, espessura do xilema e floema na região interfascicular e a área do xilema e floema na região fascicular encontram-se nas Tabelas 1 a 4 .

Seções de caule de tomateiros a $5 \mathrm{~cm}$ do solo, aos 10 e 20 D.A.T. com reguladores vegetais mostraram que os maiores valores de altura de células epidérmicas, foram obtidos com tratamentos com CCC e SADH (Tabela 1 e 2). A maior espessura do córtex foi observada com o tratamento NAA (Figuras 1C e 2 E,F ;
TABELA 1 e 2) e a menor espessura com SADH (Figuras 1E e 2C). O tratamento com CCC, aumentou a espessura do córtex em relação aos tratamentos com $\mathrm{GA}_{3}$ e $\mathrm{SADH}$ e pouco diferiu da testemunha. Essigmann et al. (1982) observaram que o volume celular do córtex de feijoeiros tratados com CCC dobrou em relação ao controle.

A espessura do colênquima foi ampliada pelo NAA (Tabela 1 e 2) e reduzida pelo SADH, em relação à testemunha e aos demais tratamentos (Figuras $1 \mathrm{~A}$ a E). A espessura do floema na região interfascicular ( R.I. ), a $5 \mathrm{~cm}$ do solo e na região mediana (Tabela 1 a 4) foi maior para o tratamento com NAA, sendo que os valores obtidos para os demais tratamentos não diferiram entre si (Figuras 1C e $2 \mathrm{~A}$ a E).

$\mathrm{Na}$ região fascicular (R.F.), a área do floema externo (Tabela 1, 3 e 4 ) tendeu a ser maior para o tratamento com NAA e menor para o tratamento com SADH. O tratamento $\mathrm{GA}_{3}$ tendeu a promover um aumento de área do floema externo (Tabela 1 a 3 ), quando comparado com a testemunha.

Tabela 1. Variáveis quantitativas do caule de plantas de Lycopersicon esculentum Mill. cv. Ângela Gigante a $5 \mathrm{~cm}$ do solo submetidas aos efeitos de reguladores vegetais (10 D.A.T.). Valores médios, ALT = altura $(\mu \mathrm{m}) ; \mathrm{E}=$ espessura $(\mu \mathrm{m}) ; \mathrm{A}=$ área (mm2); R.I.=regiões interfasciculares; R.F. região fascicular.

\begin{tabular}{|c|c|c|c|c|c|c|c|c|}
\hline \multirow[b]{2}{*}{ Tratamentos } & \multicolumn{8}{|c|}{ Parâmetros } \\
\hline & $\begin{array}{l}\text { Epiderme } \\
\text { ( ALT ) }\end{array}$ & $\begin{array}{l}\text { Córtex } \\
\text { (E) }\end{array}$ & $\begin{array}{l}\text { Colênquima } \\
\text { (E) }\end{array}$ & $\begin{array}{l}\text { Floema } \\
\text { (E) R.I. }\end{array}$ & $\begin{array}{l}\text { Xilema } \\
\text { (E) R.I. }\end{array}$ & $\begin{array}{l}\text { Floema } \\
\text { externo } \\
\text { (A) R.F. }\end{array}$ & $\begin{array}{l}\text { Floema } \\
\text { interno } \\
\text { (A) R.F. }\end{array}$ & $\begin{array}{l}\text { Xilema } \\
\text { (A) R.F. }\end{array}$ \\
\hline Testemunha & 14,2 & 360,4 & 175,2 & 104,8 & 251,2 & 0,204 & 0,044 & 0,431 \\
\hline GA 50 ppm & 12,0 & 280,8 & 160,8 & 100,4 & 224,4 & 0,291 & 0,035 & 0,555 \\
\hline NAA 100ppm & 14,2 & 601,6 & 411,6 & 209,2 & 226,4 & 0,420 & 0,028 & 0,252 \\
\hline CCC1500 ppm & 16,0 & 380,0 & 261,6 & 106,0 & 46,8 & 0,235 & 0,058 & 0,263 \\
\hline SADH 3000ppm & 16,0 & 244,0 & 155,2 & 122,4 & 82,0 & 0,196 & 0,024 & 0,116 \\
\hline
\end{tabular}

Tabela 2. Variáveis quantitativas do caule de plantas de Lycopersicon esculentum Mill. cv. Ângela Gigante a $5 \mathrm{~cm}$ do solo submetidas aos efeitos de reguladores vegetais ( 20 D.A.T.). ALT= altura $(\mu \mathrm{m}) ; \mathrm{E}=$ espessura $(\mu \mathrm{m}) ; \mathrm{A}=$ área (mm2); R.I.= região interfascicular; R.F .=Região fascicular.

\begin{tabular}{|c|c|c|c|c|c|c|c|c|}
\hline \multirow[b]{2}{*}{ Tratamentos } & \multicolumn{8}{|c|}{ Parâmetros } \\
\hline & $\begin{array}{l}\text { Epiderme } \\
\text { ( ALT ) }\end{array}$ & $\begin{array}{l}\text { Córtex } \\
\text { ( E ) }\end{array}$ & $\begin{array}{l}\text { Colênquima } \\
\text { (E) }\end{array}$ & $\begin{array}{l}\text { Floema } \\
\text { (E) R.I. }\end{array}$ & $\begin{array}{l}\text { Xilema } \\
\text { (E) R.I. }\end{array}$ & $\begin{array}{l}\text { Floema } \\
\text { externo } \\
\text { (A) R.F. }\end{array}$ & $\begin{array}{l}\text { Floema } \\
\text { interno } \\
\text { (A) R.F. }\end{array}$ & $\begin{array}{l}\text { Xilema } \\
\text { (A) R.F }\end{array}$ \\
\hline Testemunha & 14,0 & 235,6 & 130,8 & 98,4 & 272,4 & 0,562 & 0,032 & 375,6 \\
\hline GA 50 ppm & 12,8 & 220,8 & 139,6 & 113,2 & 334,8 & 0,556 & 0,040 & 448,0 \\
\hline NAA 100ppm & 14,6 & 634,4 & 374,8 & 233,6 & 346,8 & 0,416 & 0,040 & 580,4 \\
\hline CCC1500 ppm & 16,0 & 268,8 & 196,4 & 151,2 & 193,6 & 0,364 & 0,038 & 344,8 \\
\hline SADH 3000ppm & 16,0 & 350,0 & 225,6 & 130,4 & 160,4 & 0,578 & 0,081 & 290,8 \\
\hline
\end{tabular}




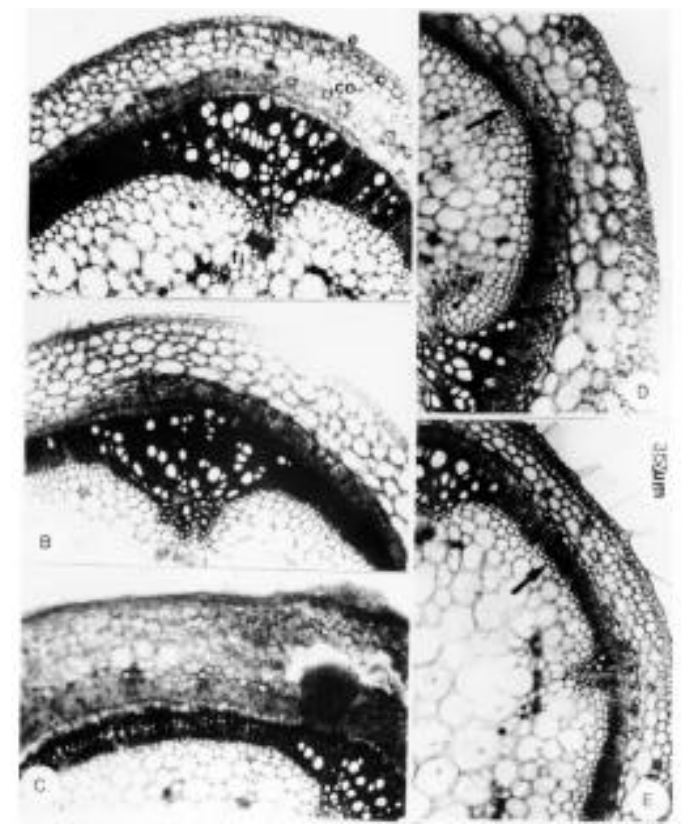

Figura 1- Seção transversal na região de entrenó do caule de plantas de Lycopersicon esculentum Mill. cv. Ângela Gigante, a $5 \mathrm{~cm}$ do solo, submetidas aos efeitos de reguladores vegetais (10 D.A.T.). A- Testemunha, B- GA 50 mg.L ${ }^{-1}$, C-NAA $100 \mathrm{mg} \cdot \mathrm{L}^{-1}$, D- CCC $1500 \mathrm{mg} \cdot \mathrm{L}^{-1}$ e E- SADH $3000 \mathrm{mg} \cdot \mathrm{L}^{-1}$. (c=colênquima; co=córtex; e=epiderme; fi=floema interno da região fascicular, As setas indicam a região interfascicular).

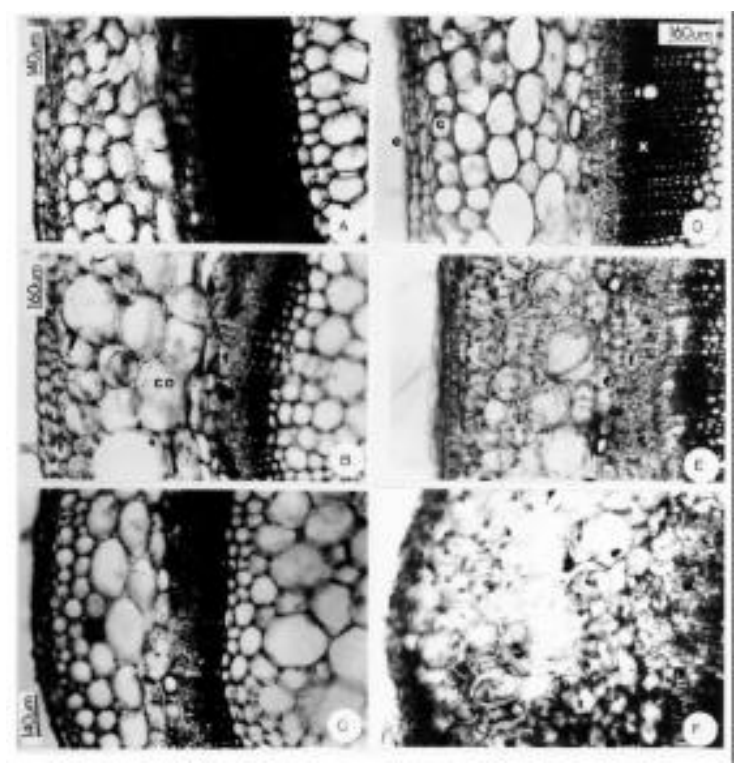

Figura 2- Seção transversal na região de entrenó do caule de plantas de Lycopersicon esculentum Mill. cv. Ângela Gigante, a $5 \mathrm{~cm}$ do solo, submetidas aos efeitos de reguladores vegetais (10 D.A.T.). Pormenor da região interfascicular. A- Testemunha, B- CCC 1500 mg.L ${ }^{-1}$, C- SADH 3000 mg.L ${ }^{-1}$, D- GA 50 mg.L $L^{-1}$, Ee FNAA $100 \mathrm{mg} \cdot \mathrm{L}^{-1}$. (c=colênquima; co=córtex; e=epiderme; f=floema; $\mathrm{x}=x$ ilema). 
Segundo Demaggio (1966) a giberelina é ativa na estimulação da diferenciação de novos elementos do tubo crivoso. Houve pequena variação na área do floema interno em relação a testemunha ( Tabela 1 a 4).

A espessura do xilema na região interfascicular (Figura $3 \mathrm{~A}$ a $\mathrm{C}$ ), praticamente não diferiu da testemunha para os tratamentos com $\mathrm{Ga}_{3}$ e NAA( Tabela 1 a 4), porém os tratamentos com CCC e SADH ocasionaram redução na espessura do xilema (Figura 3 D a E). Nota-se que nessa região, em caules tratados com $\mathrm{GA}_{3} \mathrm{e}$ NAA, ocorreu aumento do número de elementos traqueais, enquanto que nos demais tratamentos verificou-se a formação de fibras. Gonçalves (1984), observou que plantas de cana-de-açúcar 'NA 56-79', tratadas com GA 50 $\mathrm{mg} . \mathrm{L}^{-1}, \quad$ apresentaram intensa atividade meristemática, levando a contínua formação de feixes vasculares, com menor quantidade de fibras.

Segundo Digby \& Wareing (1966) e Fosket \& Torrey (1969), a auxina é geralmente reconhecida como um fator limitante para a diferenciação do xilema. Ela tem importância na promoção do alongamento das derivadas cambiais que sofrem diferenciação em elementos de vaso e fibras. Embora a giberelina estimule a divisão celular do câmbio do caule, não é ela que promove a diferenciação do xilema.

Aos 10 D.A.T., nota-se que o $\mathrm{GA}_{3}$ provocou um pequeno aumento na área do xilema na região fascicular ( R.F.) quando comparado com a testemunha ( Tabela 1). Nos demais tratamentos houve uma redução na área do xilema. Aos 20 D.A.T. observa-se expansão da área do xilema na região fascicular, para os tratamentos $\mathrm{GA}_{3} \mathrm{e}$ NAA, em relação aos demais tratamentos (Tabela 2 ). Os tratamentos $\mathrm{GA}_{3}$ e NAA consequentemente, aumentaram a concentração de lignina com a produção de elementos de vaso, esse aumento na concentração de lignina também foi observado no trabalho de Marigo \& Boudet (1980), em tomateiros.

Seções do caule a $5 \mathrm{~cm}$ do solo aos 10 e 20 D.A.T., tratados com retardadores de crescimento (CCC e SADH), diminuiram a espessura do xilema na região fascicular e interfascicular (Tabela 1 a 2). O tratamento com NAA aos 10 e 20 D.A T., provocou aumento na espessura do córtex e colênquima ( Figura 5 C).

Tabela 3. Variáveis quantitativas da região mediana do caule de plantas de Lycopersicon esculentum Mill. cv. Ângela Gigante, submetidas aos tratamentos com reguladores vegetais (10 D.A.T.). ALT= altura $(\mu \mathrm{m})$; $\mathrm{E}=$ espessura $(\mu \mathrm{m}) ; \mathrm{A}=$ área $(\mathrm{mmm} 2)$; R.I. =Região interfascicular; R.F.= Região fascicular

\begin{tabular}{|c|c|c|c|c|c|c|c|c|}
\hline \multirow{2}{*}{$\begin{array}{l}\ldots . . \\
\text { Tratamentos }\end{array}$} & \multicolumn{8}{|c|}{ Parâmetros } \\
\hline & $\begin{array}{l}\text { Epiderme } \\
\text { ( ALT) }\end{array}$ & $\begin{array}{l}\text { Córtex } \\
\text { (E) }\end{array}$ & $\begin{array}{l}\text { Colênquima } \\
\text { (E) }\end{array}$ & $\begin{array}{l}\text { Floema } \\
\text { (E)R.I. }\end{array}$ & $\begin{array}{l}\text { Xilema } \\
\text { (E)R.I. }\end{array}$ & $\begin{array}{l}\text { Floema } \\
\text { externo } \\
\text { (A) R.F. }\end{array}$ & $\begin{array}{l}\text { Floema } \\
\text { interno } \\
\text { (A) R.F. }\end{array}$ & $\begin{array}{l}\text { Xilema } \\
\text { (A) R.F. }\end{array}$ \\
\hline Testemunha & 15,2 & 187,2 & 122,8 & 95,2 & 67,2 & 0,252 & 0,031 & 0,101 \\
\hline GA $50 \mathrm{ppm}$ & 16,0 & 153,2 & 112,8 & 87,2 & 85,6 & 0,292 & 0,028 & 0,220 \\
\hline NAA 100ppm & 16,0 & 314,4 & 198,0 & 301,2 & 151,2 & 0,302 & 0,021 & 0,363 \\
\hline CCC1500 ppm & 16,0 & 196.8 & 125,2 & 62,0 & 50,0 & 0,302 & 0,036 & 0,135 \\
\hline SADH 3000ppm & 14,6 & 192,8 & 130,0 & 77,6 & -- & 0,201 & 0,027 & 0,054 \\
\hline
\end{tabular}

Tabela 4. Variáveis quantitativas da região mediana do caule de plantas de Lycopersicon esculentum Mill. cv. Ângela Gigante, submetidas aos tratamentos com reguladores vegetais (20 D.A.T.). ALT= altura $(\mu \mathrm{m}) ; \mathrm{E}=\mathrm{espessura}$ $(\mu \mathrm{m}) ; \mathrm{A}=$ área (mm2); R.I.=Região interfascicular ; R.F.=Região fascicular.

\begin{tabular}{|c|c|c|c|c|c|c|c|c|}
\hline \multirow[b]{2}{*}{ Tratamentos } & \multicolumn{8}{|c|}{ Parâmetros } \\
\hline & $\begin{array}{l}\text { Epiderme } \\
\text { ( ALT) }\end{array}$ & $\begin{array}{l}\text { Córtex } \\
\text { (E) }\end{array}$ & $\begin{array}{l}\text { Colênquima } \\
\text { (E) }\end{array}$ & $\begin{array}{l}\text { Floema } \\
\text { (E) R.I. }\end{array}$ & $\begin{array}{l}\text { Xilema } \\
\text { (E)R.I. }\end{array}$ & $\begin{array}{l}\text { Floema } \\
\text { Externo } \\
\text { (A) R.F. }\end{array}$ & $\begin{array}{l}\text { Floema } \\
\text { interno } \\
\text { (A) R.F. }\end{array}$ & $\begin{array}{l}\text { Xilema } \\
\text { (A) R.F. }\end{array}$ \\
\hline Testemunha & 16,0 & 162,4 & 114,4 & 92,4 & 122,8 & 0,184 & 0,021 & 215,2 \\
\hline GA 50 ppm & 16,0 & 146,8 & 102,0 & 78,0 & 101,2 & 0,169 & 0,025 & 179,2 \\
\hline NAA 100ppm & 16,0 & 404,4 & 269,0 & 266,8 & 388,4 & 0,416 & 0,021 & 655,2 \\
\hline CCC1500 ppm & 16,0 & 217,2 & 157,6 & 99,6 & 65,2 & 0,194 & 0,042 & 164,8 \\
\hline SADH 3000ppm & 15,2 & 256,0 & 184,8 & 100,0 & 104,4 & 0,226 & 0,051 & 204,4 \\
\hline
\end{tabular}




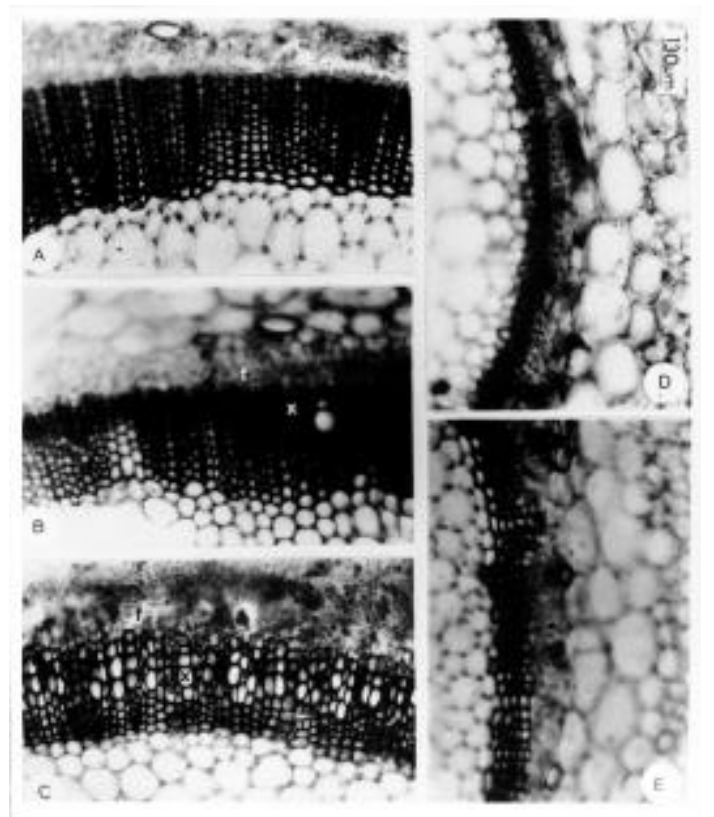

Figura 3. Seção transnsversal na região de entrenó do caule de plantas de Lycopersicon esculentum Mill. cv. Ângela Gigante, a $5 \mathrm{~cm}$ do solo, submetidas aos efeitos de reguladores vegetais (10 D.A.T.).Pormenor da região interfascicular. A-Testemunha, B-GA $50 \mathrm{mg} . \mathrm{L}^{-1}$, C- NAA $100 \mathrm{mg} . \mathrm{L}^{-1}$,D- CCC $1500 \mathrm{mg} . \mathrm{L}^{-1}$ e E-SADH3000 mg.L ${ }^{-1}$ (f-floema; x-xilema).

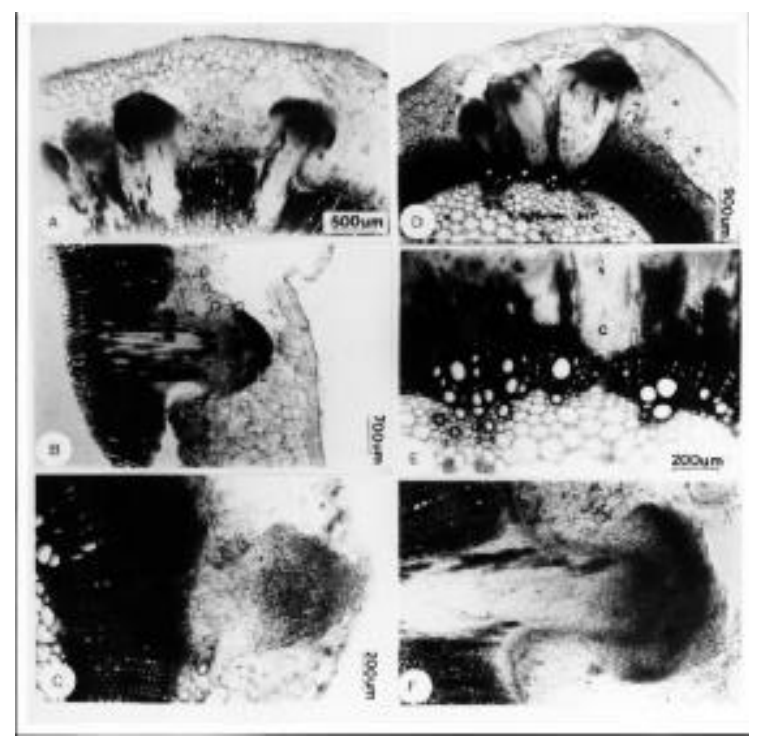

Figura 4. Seção transversal na região do entrenó do caule de plantas de Lycopersicon esculentum Mill. cv. Ângela Gigante, a $5 \mathrm{~cm}$ do solo, submetidas aos efeitos de reguladores vegetais ( 20 D.A.T.). A,B,D-F- NAA 100 mg.L ${ }^{-1}$; CGA $50 \mathrm{mg} . \mathrm{L}^{-1}$; E- detalhe da formacão de raiz adventícia na região fascicular a partir de células do câmbio vascular. (c- câmbio vascular).

Houve hipertrofia das células do parênquima e do colênquima, quando comparadas com as dos demais tratamentos (Figura 5 A, B, D a F).
O tratamento com $\mathrm{GA}_{3}$ e NAA 10 D.A.T., provocou aumento na área do xilema na região fascicular (Figura 6 B, C) e o tratamento com $\mathrm{SADH}$ causou uma diminuição da área de 
xilema (Figura 6 E e Tabela 3), quando comparados com a testemunha e com os demais tratamentos (Figura $6 \mathrm{~A}$ a D).

$\mathrm{Na}$ região fascicular, o tratamento com NAA mostrou a formação de xilema descontínuo, com células de parênquima separando cordões de elementos traqueais e fibras (Figura $7 \mathrm{C}$ ). A área do floema interno não apresentou diferenças marcantes entre os tratamentos aos 10 e 20 D.A.T. (Tabelas 3 e 4). Em relação a área do floema externo na região mediana do caule, a 10 D.A.T., praticamente não houve diferença entre os tratamentos, porém aos 20 D.A.T., observou-se um aumento na área de floema para os tratamentos com NAA (Tabela 3).

$\mathrm{Na}$ região interfascicular do caule a 10 e 20 D.A.T., observou-se que o tratamento com NAA provocou um aumento na espessura do floema e xilema (Tabelas 3 e 4 ), quando comparado aos demais tratamentos ( Figuras 5 A a F). Scott
(1938) foi o primeiro a constatar que a auxina sozinha pode ter função na formação de células de floema. A formação do xilema, pode também ser estimulada por giberelina

(Bradley\& Crane ,1957; Wareing, 1958 ) e a maturação dos vasos também pode estar sob o controle de giberelina (Wareing,1958; Doley \& Leyton, 1968), esses resultados estão de acordo com este trabalho.

Digby \& Wareing (1966) constataram que a auxina sozinha ativava a formação e a maturação de células de xilema, porém não promovia a iniciação ou a maturação de células de floema. Porém, a giberelina sozinha acelerava a formação, mas não a maturação de células de xilema e floema.

Hejnowicz \& Tomaszewski (1969) sugeriram que deve haver certo balanço entre giberelina e auxina para se obter máxima diferenciação do xilema.

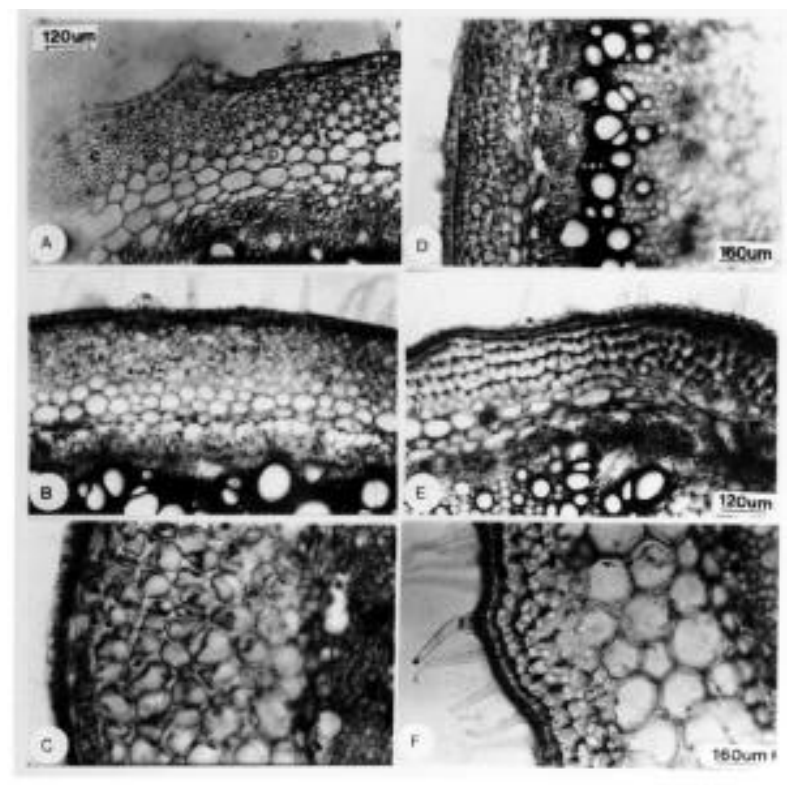

Figura 5 . Seção transversal da região mediana do entrenó do caule de plantas de Lycopersicon Ângela Gigante, submetidas aos efeitos de reguladores vegetais (10 D.A.T.). A- Testemunha ; B- GA 50 mg.L L $^{-1}$ NAA 100 mg.L N $^{-1} \quad{ }^{-1}$; E-F- SADH 3000 mg.L . (c-colênquima; p-parênquima cortical). 


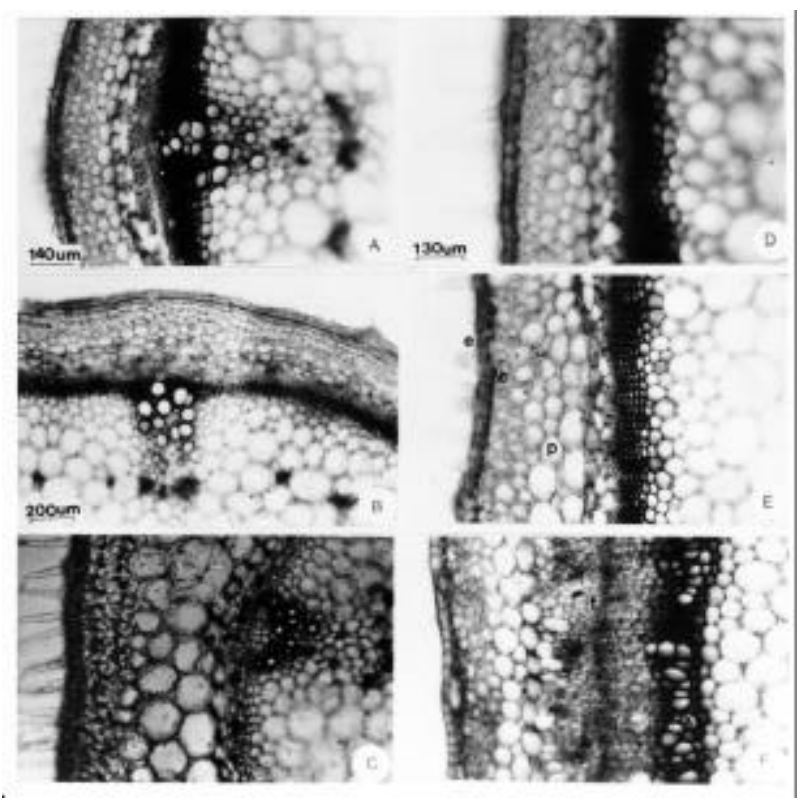

Figura 6. Seção transversal da região mediana do entrenó do caule de plantas de Lycopersicon esculentum Mill. cv. Ângela Gigante, submetidas aos efeitos de reguladores vegetais ( 10 D.A.T.). Detalhes da região interfascicular.A e D - Testemunha, B- CCC 1500 mg.L ${ }^{-1}$, C- SADH 3000 mg.L ${ }^{-1}$, E- GA 50 mg.L ${ }^{-1}$, F- NAA $100 \mathrm{mg} . \mathrm{L}^{-1}$. (c- colênquima; e- epiderme; f- floema; p- parênquima; $\mathrm{x}$ - xilema).

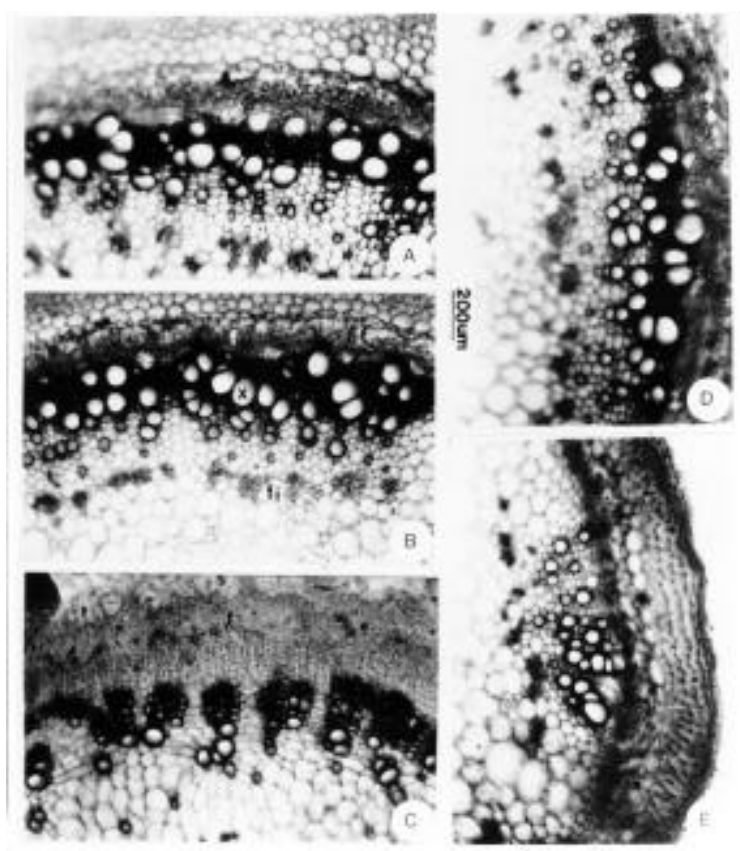

Figura 7. Seção transversal da região mediana do entrenó do caule de plantas de Lycopersicon esculentum Mill. cv. Ângela Gigante, submetidas aos efeitos de reguladores vegetais (10 D.A.T.). Detalhes da região fascicular. A-

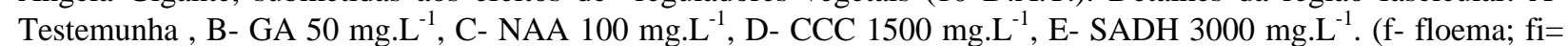
floema interno; $\mathrm{x}$ - xilema).

Em dicotiledôneas evidenciou-se que a concentração e o fluxo de auxinas, são fatores limitantes para a diferenciação de elementos de tubo crivado e traqueais (Thompson \&
Jacobs, 1966; Aloni, 1980; Aloni \& Zimmermann, 1983). 
A produção de auxinas nas folhas, regula a de muitas plantas (Sachs, 1981;

Wareing, 1981). A aplicação exógena de auxina

formação de vaso e lignificação em

plátano (Acer ) e caules de choupo ( nigra v. itálica ) e freixo Fraxinus excelsior ), Wareing, 1958.

wareing et al. (1964) observaram que novos Populus e em resposta ao tratamento com ácido giberélico.

outras substâncias, como açúcares e minerais, também podem estar envolvidos, além da

tomateiros, a $5 \mathrm{~cm}$ do solo, os reguladores vegetais GA e NAA promoveram a diferenciação de raízes

células do câmbio vascular (Figuras 4 A a F).

região mediana do caule sob efeito do tratamento com NAA. AgarwaL (1979) verificaram que tratamentos com

em caules de tomateiros cortados, afetou favoravelmente a formação de raízes, a brotações e subsequientemente, $\mathrm{o}$

crescimento. No entanto, Staden

(1985) verificaram que o tratamento com

Aloni, R. (1980), Role of auxins and in the sieve and tracheary 150, 255-263 in plant cultures. Planta

Zimmermann, M.H.(1983), The vessel size and along the axis- a new

Differentiation.

24, 203-208.

Crane, J.C.(1957), Gibberellinactivit in

apricot spur Science. Washington , , 972-973.

Doley, D.\&

Effects of growth substances and water

on the secondary xylem

Fraxinus. New Phytol. London, 67 579-594. e giberelina não estimulou o crescimento da raiz

\section{CONCLUSÕES}

Com base nos resultados anatômicos, realizados

Lycopersicon esculentum Mill., submetidos aos efeitos de reguladores vegetais e nas condições

concluir que:

1) A espessura do xilema na região interfascicular foi maior para os tratamentos

2)

fascicular, o tratamento com NAA mostrou a formação de xilema separando cordões de elementos parênquima e fibras.

3) Os tratamentos com CCC e $\mathrm{SADH}$ provocaram diminuição da espessura do

4)

aumentaram a concentração de lignina, com

5)

induziram a formação de raízes adventícias à partir de células do câmbio vascular.

Demaggio, A.E. (1966), Induced

differentiation: Science. by gibberellic 152, 370-372. Wareing, P.F. (1966), The applied growth on cambial division and differentiation of the derivaties. Ann. Bot. London, , 539-548

Gautié, A. Manuel de technique Lamane, 1909, $534 \mathrm{p}$.

Finnie , J.F. \&

Effect of seaweed hormones in vitro applied Struttgart, 120

Fosket, D. E. \& Torrey, J .C.(1969), Hormonal cell proliferation and differentiation in tissues of 
Glycine max var. Bilox. Plant Physiology, 44, 871-880.

Gonçalves, M.B. Efeitos de Giberelina e Ethephon no crescimento inicial, nutrição mineral, morfologia e anatomia de canade-açúcar. Piracicaba: ESALQ, 1984. 123p. Dissertação (Mestrado em Agronomia) - Escola Superior de Agricultura ' Luiz de Queiroz'- USP, 1984.

Harrison, M.A. \& Klein, R.M. (1979), Role of growth regulators in initiation of secondary xylem and phloem cells. Botanical Gazette, Chicago, 140(1), 2024.

Hathout, T.A.; Sheteawi, S.A.\& Khallal, S. M. (1993a), Effect of mode application of some growth regulators on the physiology of tomato plants. I Effect of indole-acetic (IAA) on morphology, growth, metabolism and productivity. Egyptian Journal of Physiological Sciences ,17 (1), 17-43.

Hathout, T.A.; Sheteawi, S.A. \& Khallal,S.M. (1993b), Effect of mode application of some growth regulators on the physiology of tomato plants. II Effect of IAA on the endogenous hormonal contents. Egyptian Journal of Physiological Sciences, 17(1),45-62.

Hejnowicz, A. \& Tomaszewski, M. (1969), Growth regulators and wood formation in Pinus silvestris. Physiol. Plant. Copenhagen, 22, 984-992.

Kumar,P. \& Agarwal, A.K.(1979), Influence of auxin and morphactin on rooting, sprouting of buds cuttings. Acta . Bot. Indica. Merrut, 7(2), 133-138.

Marigo, G, \& Boudet, A.M. (1980), Polyphenols and growth : Lignification and limitation of growth in Lycopersicon esculentum. Physiol.Plant. Copenhagen, 49 (4), 42530.
Sachs, T. (1981), The control of the patterned differentiation of vascular tissues. $A d v$. Bot. Res. New York, 9, 151-262.

Savidge, R.A. \& Wareing, P.F. (1981), Plant growth regulators and the differentiation of vascular elements, p. 192-235. In: J.R. Barnett (ed). Xylem cell development, tracheid differentiation factor from pine needles. Planta. Berlin, 153, .395-404.

Scott, F.M. (1938), Anatomy of auxin- treated etiolated seedlings of Pisum sativum.Bot. Gaz. Chicago, 100, 167-185.

Shininger, T.L. (1970), The production and differentiation of secondary xylem in Xanthium pensylvanicum. Amer. J. Bot. New York, .57, 769-781.

Shininger, T.L. (1971), The regulation of cambial division and secondary differentiation in Xanthium by auxins and gibberellin.. Plant. Physiol. Lancaster, 47, 417-422.

Sorokin, H.P., Mathur, S.N., \& Thimann, K.V. (1972), The effects of auxins and kinetin on xylem differentiation in the Pea epicotyl. Amer. J. Bot., 49, 444-454.

Stand, M.Y.(1961), The effects of gibberellic acid on fibre cell lenght. Annals of Botany N.S. 25(100), 453-462.

Thompson, N. P. \& Jacobs, W. P. (1966), Polarity of IAA effect on sieve- tube and xylem regeneration in Coleus and tomato stems. Plant. Physiol. Lancaster, 41, 637682.

Wareing, P. F.(1958), Interation between indoleacetic acid and gibberellic acid in cambial activity. Nature. London, 181, 1744-1745

Wareing, P. F., Hanney, C.E.A. \& Digby, J. The role of endogenous hormones in cambial activity and xylem differentiation. In: ZIMMERMANN, M. H. The formation of wood in forest trees. New York, (ed.). Academic Press, 1964, p. 323-44. 